\title{
URINARY MARKERS OF OXIDATIVE DNA DAMAGE IN TYPE 1 DIABETIC CHILDREN: RELATION TO MICROVASCULAR COMPLICATIONS
}

\author{
MAGED A. EL WAKEEL ${ }^{1 *}$, MOHAMED ABOU-EL-ASRAR ${ }^{2}$, GHADA M. EL-KASSAS ${ }^{1}$, MONA A ELABD ${ }^{1}$, DINA ABU \\ ZEID $^{1}$, RANIA N SABRY ${ }^{1}$, EMAN AWADALLAH ${ }^{3}$
}

${ }^{1}$ Department of Child Health, National Research Centre, Cairo, Egypt. ${ }^{2}$ Department of Pediatrics, Faculty of Medicine, Ain Shams University, Egypt. ${ }^{3}$ Department of Clinical and Chemical Pathology, National Research Centre, Cairo, Egypt. Email: maged_elwakeel@yahoo.com

\author{
Received: 05 May 2017, Revised and Accepted: 04 July 2017
}

ABSTRACT

Objective: Type 1 diabetes mellitus (T1DM) is a widespread metabolic disease, which frequently carries with it a significant impact on human health. Oxidative damage and tissue inflammation have been claimed to be a typical pathogenic component for the progression of diabetic complications. We aim in this study to explore the relation of urinary 8-oxo-7,8-dihydro-2'-deoxyguanosine (8-oxodG) (as a marker of nucleic acid oxidation) to microvascular complications in T1DM.

Methods: A case-control study, enrolling 45 T1DM children and an equivalent number of healthy subjects, was performed. Full clinical examination and anthropometric measurement were performed to all subjects. Urinary assessment for 8-oxodG and albumin was done in addition to blood sampling for lipid profile and glycated $\mathrm{Hb}(\mathrm{HbA1c})$ assay. Complete ocular examination for assessment of diabetic retinopathy (DR) was also done.

Results: Levels of urinary 8-oxodG, serum cholesterol, triglycerides, and low-density lipoprotein in cases were significantly higher than non-diabetics; these levels were likewise higher in uncontrolled T1DM patients in comparison with well-controlled T1DM subjects. Urinary 8-oxodG and HbA1c were significantly higher in diabetic patients with albuminuria and DR compared to patients without complications. Significant positive correlation was found between 8-oxodG with $\mathrm{HbA1c}(\mathrm{r}=0.8, \mathrm{p}<0.01)$, diastolic blood pressure (DBP) $(\mathrm{r}=0.4, \mathrm{p}=0.02)$, and cholesterol $(\mathrm{r}=0.4$, $\mathrm{p}=0.05)$.

Conclusion: Urinary 8-oxodG was found to be a reliable marker for assessing oxidative DNA damage in T1DM and can be used in the determination of microvascular complications related to diabetes.

Keywords: Urinary 8-oxo-7,8-dihydro-2'-deoxyguanosine, Type1 diabetes, DNA oxidation, Microvascular complications

(C) 2017 The Authors. Published by Innovare Academic Sciences Pvt Ltd. This is an open access article under the CC BY license (http://creativecommons. org/licenses/by/4. 0/) DOI: http://dx.doi.org/10.22159/ajpcr.2017.v10i10.18930

\section{INTRODUCTION}

Type 1 diabetes mellitus (T1DM) is considered one of the most frequent endocrine diseases in children. These young children confront a long period of hyperglycemia in their prepubertal years with the danger of early occurrence of micro- and macrovascular complications [1]. In spite of the fact that complications from T1DM are rare among children, endothelial dysfunction which is an early pointer of vascular insufficiency may happen $[2,3]$. Around $80 \%$ of patients with diabetes die from thrombotic events; $75 \%$ of these passings are because of cardiovascular complications and the rest due to cerebrovascular and peripheral vascular diseases [4].

The role of oxidative damage in the mechanisms of diabetic hazards was the focus of interest in the previous years. Expanded levels of markers of oxidative stress were obvious in the diabetic state, and recent reviews showed that oxidative stress plays a crucial role in mediating the pathophysiology of these complications [5,6]. DNA oxidation marker (8-oxodG) is a novel biomarker that could be used as a marker of oxidative stress in diabetes. Urinary levels of this biomarker can be evaluated in urine as a noninvasive technique; this makes it an easier way for hazard detection and management plan $[7,8]$.

The most frequently measured urinary marker of oxidative stress, and for diabetic complications in adult (Type 2 diabetes) is 8-OxodG [9], however, no enough studies focusing on this marker concentration in diabetic children and adolescents (Type 1). In this study, we aimed to assess the urinary 8-OHdG diagnostic ability in the identification of microvascular complications in T1DM.

\section{METHODS}

This was a case-control study. 45 diabetic children and adolescents with T1DM attending Pediatric Diabetic Clinic of Children Hospital, Ain Shams University, and 45 matched healthy subjects aged 6-16 years were included. T1DM patients were further subdivided according to HbA1c into Group I with HbA1C of 8\% or less (well-controlled T1DM) and Group II with $\mathrm{HbA1c}>8 \%$ (poorly controlled T1DM).

Subjects were excluded for any of the following reasons: Presence of acute infection at the time of testing; medications or hormones (other than insulin); the presence of known renal disease; or systemic disease and other chronic or inflammatory disease. After taking a written informed consent from the parents of children enrolled in the study, each child was subjected to a complete physical examination, a detailed medical history, and anthropometric measurements. Their weight was measured using a digital scale (Seca, Hamburg, Germany) to the nearest $0.1 \mathrm{~kg}$ with the children dressed in minimal clothes and without shoes. Their height was measured using a Seca 225 stadiometer to the nearest $0.1 \mathrm{~cm}$ [10]. The body mass index (BMI) was calculated as the weight $(\mathrm{kg})$ divided by the height $(\mathrm{m})$ squared. Weight, height, and BMI standard deviation score (SDS) were assessed using the new WHO reference [11]. Blood pressure (BP) was measured by a sphygmomanometer (Accoson, London, UK) as the mean of two measurements. BP (SDS) was determined using the German references [12].

About $3 \mathrm{ml}$ of venous blood samples after an $8 \mathrm{hrs}$ fasting were collected from each subject in sterile plain vacutainer tubes. Blood on the plain tubes was allowed to clot for 30 minutes, and then centrifuged 
at $3000 \times \mathrm{g}$ for 10 minutes then the serum was separated and frozen at $-20^{\circ} \mathrm{C}$ until the time of assay to avoid erroneous results from repeated freeze/thaw cycles. Total cholesterol and triglyceride and high-density lipoprotein (HDL) were determined using colorimetric techniques on Synchron Cx7 (Beckman Instruments Inc., California, USA). Lowdensity lipoprotein (LDL) cholesterol was measured by Friedwald et al. formula [13]. Fasting blood glucose level was performed on automated clinical chemistry analyzer (OLYMPUS AU400)

Early morning urine samples were collected, centrifuged at $3000 \times \mathrm{g}$ for 10 minutes as any precipitation may affect analysis of albumin in urine, and then the supernatant was stored at $-20^{\circ} \mathrm{C}$ till albumin and creatinine measurement, as a variations in urine flow rate are corrected by expressing albumin as a ratio to creatinine (mg albumin/gram creatinine) where values $<30$ is normal, $30-300$ there is microalbuminuria, $>300$ show macroalbuminuria.

Albumin in urine was performed on a spectrophotometer (BioSystems BTS-302) using BioSystems kit (BioSystem S.A. Costa Brava, 30.08030 Barcelona [Spain]). Creatinine in urine was measured on a spectrophotometer (BioSystems BTS-302) using BIODIAGNOSTIC kit (colorimetric Kinetic Method) [14].

Human 8-oxo 7.8 dihydro-2deoxyguanisine was assayed in urine using human 8-oxo 7.8 dihydro-2 deoxyguanisine ELISA kit, Kono Biotech Co., Ltd. The result was expressed as a ratio to urinary creatinine to correct the variation in urinary flow.

Diabetic retinopathy (DR) was diagnosed by doing complete ocular examination including visual field testing, slit-lamp biomicroscopy, and indirect ophthalmoscopy. Fundus examination was performed through dilated pupils using 90-diopter Volk lens and biomicroscope. The presence and grading of DR were based on the International clinical DR and macular edema disease severity scale [15].

\section{Statistical analyses}

Data entry was carried on excel sheet, and statistical analysis was performed using SPSS software program version 18.0 (IBM, Chicago, IL, USA). Data were analyzed, characteristics of the sample were presented; mean and standard deviation were estimated as regarding age, BMI (SDS), systolic and diastolic BP (SDS), the level of HbA1C, cholesterol, triglyceride, and level of 8-oxodG. On the other hand, numbers and percentages were calculated as regard sex distribution and presence of albuminuria. Chi-square was done for comparison of qualitative data that presented by numbers and percentages, t-test was done for comparison between two means, and Pearson Correlation was done for relations between two quantitative variables. Linear regression analysis was performed to predict risk factors significantly associated with increased level of 8-oxodG. p value was considered statistically significant when $\mathrm{p}<0.05$ and considered statistically highly significant when its value was $<0.01$.

\section{RESULTS}

A total of 90 children were recruited in our study: 44 Type 1 diabetic children and an equal number of healthy children as controls. Demographic and laboratory data of studied cases are shown in Table 1.

There was no difference between cases and controls regarding age or gender. Mean levels of urinary 8-oxodG, serum cholesterol, triglycerides (TG), LDL and as expected, HbA1c, showed a significant increase in T1DM children compared to control. Meanwhile, the mean value of anthropometric measurements was indifferent between the two groups (Table 1). $26 \%$ of patients had albuminuria with a mean duration of illness of 8.2 years.

Uncontrolled T1DM patients had higher diastolic BP (DBP) SDS, urinary 8-oxodG, serum cholesterol, TG and LDL levels compared to the wellcontrolled diabetic group. Albuminuria, measured in mg/gm creatinine, was also higher in poorly controlled patients (Table 2).
Table 3 shows that diabetic children with albuminuria had higher levels of urinary 8-oxodG, $\mathrm{HbA}_{1} \mathrm{c}$ and higher values of DBP (SDS) compared to non-albuminuric patients, while no difference in levels of lipid profile or anthropometric measurements was found regarding the presence of albuminuria. Urinary 8-oxodG levels were also found to be higher in cases diagnosed with retinopathy compared to other cases (Fig. 1).

Correlation analysis between urinary 8-oxodG and lipid profile, BMI, $\mathrm{BP}$ (SDS), glycated $\mathrm{Hb}$, duration of illness in diabetic children revealed positive association between 8-oxodG with DBP (SDS) ( $r=0.4, p=0.02)$, glycated $\mathrm{Hb}(\mathrm{r}=0.8, \mathrm{p}<0.001)$ (Fig. 2), and serum cholesterol $(\mathrm{r}=0.4$ $\mathrm{p}=0.05$ ). There was no significant correlation between 8-oxodG and other parameters. Significant positive correlations were also found between DBP (SDS) and duration of diabetes $(r=0.4, p=0.05)$ and HbA1c $(\mathrm{r}=0.5, \mathrm{p}=0.02)$.

Linear regression analysis was applied to recognize factors influencing 8-oxodG serum levels. HbA1c was found to be the most effective factor predicting the level of urinary 8-oxodG followed by DBP and serum cholesterol (Table 4).

Table 1: Baseline characteristics and biochemical parameters of the studied population

\begin{tabular}{llll}
\hline Variables & \multicolumn{2}{l}{ Mean \pm SD } & p value \\
\cline { 2 - 3 } & Cases n=45 & Control n=45 & \\
\hline Age (years) & $10.1 \pm 3.4$ & $10.4 \pm 3.4$ & 0.7 \\
$\begin{array}{l}\text { Sex n (\%) } \\
\quad \text { Male }\end{array}$ & $20(44.4)$ & $21(46.6)$ & 0.2 \\
$\quad$ Female & $25(55.6)$ & $24(53.4)$ & \\
Weight & $0.05 \pm 1.1$ & $-0.4 \pm 1$ & 0.1 \\
Height & $-0.6 \pm 1.4$ & $-.05 \pm 1.3$ & 0.8 \\
BMI & $0.6 \pm 1.1$ & $1.1 \pm 0.6$ & 0.4 \\
DBP & $1.0 \pm 0.6$ & $0.4 \pm 0.6$ & $<0.01^{* *}$ \\
SDS & $0.9 \pm 0.8$ & $0.1 \pm 0.8$ & $<0.01^{* *}$ \\
Glycated Hb & $8.9 \pm 2.5$ & $5.3 \pm 0.4$ & $<0.01^{* *}$ \\
TG (mg/dl) & $156.8 \pm 18.9$ & $72.5 \pm 7.1$ & $<0.01^{* *}$ \\
Cholesterol (mg/dl) & $234.8 \pm 35.3$ & $139.3 \pm 16.5$ & $<0.01^{* *}$ \\
HDL (mg/dl) & $27.6 \pm 6.8$ & $52.3 \pm 4.4$ & $<0.01^{* *}$ \\
LDL (mg/dl) & $175.8 \pm 25.5$ & $72.4 \pm 18.3$ & $<0.01^{* *}$ \\
8-oxodG (ng/mg & $548.1 \pm 432.2$ & $205 \pm 109.3$ & $<0.01^{* *}$ \\
creatinine) & & & \\
\hline
\end{tabular}

** $\leq 0.01$ is highly significant, DBP: Diastolic blood pressure, BMI: Body mass index, SDS: Standard deviation score, LDL: Low-density lipoprotein, HDL: High-density lipoprotein, TG: Triglycerides

Table 2: Clinical and laboratory characteristics of Type 1 diabetic patients as regard diabetic control

\begin{tabular}{llll}
\hline Characteristics & \multicolumn{2}{l}{ Mean \pm SD } & p value \\
\cline { 2 - 3 } & $\begin{array}{lll}\text { HbA1C } \mathbf{8} 8 \\
\mathbf{n = 1 5}\end{array}$ & $\begin{array}{l}\text { HbA1C>8 } \\
\mathbf{n = 3 0}\end{array}$ & \\
\hline Weight & $-0.6 \pm 0.7$ & $0.4 \pm 1.2$ & 0.02 \\
Height & $-0.8 \pm 1.3$ & $-0.4 \pm 1.5$ & 0.5 \\
BMI & $0 \pm 0.6$ & $0.8 \pm 1.2$ & 0.5 \\
SDS & $0.7 \pm 0.2$ & $0.9 \pm 0.4$ & 0.3 \\
DBS & $0.6 \pm 0.5$ & $1.1 \pm 0.6$ & $0.03^{*}$ \\
TG (mg/dl) & $144.5 \pm 20$ & $163 \pm 15.5$ & $0.00^{* *}$ \\
Cholesterol (mg/dl) & $211.6 \pm 34.2$ & $246.4 \pm 30.4$ & $0.00^{* *}$ \\
HDL (mg/dl) & $24.6 \pm 5$ & $29.1 \pm 7$ & 0.1 \\
LDL (mg/dl) & $158 \pm 26$ & $184 \pm 20.6$ & $0.005^{* *}$ \\
8-oxodG (ng/mg & $235.5 \pm 170.5$ & $704.5 \pm 440.7$ & $0.003^{* *}$ \\
creatinine) & & & \\
Albuminuria (mg/g & $12.13 \pm 0.23$ & $54.16 \pm 40.22$ & $0.04^{*}$ \\
creatinine) & & & \\
\hline
\end{tabular}

${ }^{*} \mathrm{p} \leq 0.05$ is significant, ${ }^{* *} \mathrm{p} \leq 0.01$ is highly significant, DBP: Diastolic blood pressure, BMI: Body mass index, SDS: Standard deviation score, LDL: Low-density lipoprotein, HDL: High-density lipoprotein, ${ }^{*} \mathrm{p} \leq 0.05$ is significant, ${ }^{* *} \mathrm{p} \leq 0.01$ is highly significant, SD: Standard deviation, TG: Triglycerides 
Table 3: Clinical and laboratory characteristics of Type 1 diabetic patients as regard presence of albuminuria

\begin{tabular}{llll}
\hline \multirow{2}{*}{ Characteristics } & \multicolumn{2}{c}{ Mean \pm SD } & p value \\
\cline { 2 - 3 } & $\begin{array}{lll}\text { Absent } \\
\text { n=33 }\end{array}$ & $\begin{array}{l}\text { Present } \\
\mathbf{n}=\mathbf{1 2}\end{array}$ & \\
\hline SDS & $0.7 \pm 0.3$ & $1.1 \pm 0.7$ & 0.3 \\
DBP & $0.5 \pm 0.2$ & $1.1 \pm 0.6$ & $0.03^{*}$ \\
TG (mg/dl) & $158 \pm 21.1$ & $153.4 \pm 11.4$ & 0.6 \\
Cholesterol (mg/dl) & $236.6 \pm 39.4$ & $229.7 \pm 21.5$ & 0.6 \\
HDL (mg/dl) & $28.8 \pm 7.4$ & $24.5 \pm 4.1$ & 0.1 \\
LDL (mg/dl) & $176.3 \pm 28.6$ & $174.5 \pm 15.5$ & 0.8 \\
8-oxodG (ng/mg creatinine) & $95.0 \pm 6.4$ & $411.5 \pm 349.5$ & $0.002^{* *}$ \\
HbA1C (\%) & 8.3 & 10.4 & $0.001^{* *}$ \\
\hline *p $\leq 0.05$ is significant, **p $\leq 0.01$ is highly significant, DBP: Diastolic & \\
blood pressure, BMI: Body mass index, SDS: Standard deviation score, \\
LDL: Low-density lipoprotein, HDL: High-density lipoprotein, TG: Triglycerides
\end{tabular}

Table 4: Linear regression analysis shows predictive factors for high levels of urinary 8-oxodG in diabetic children

\begin{tabular}{|c|c|c|c|c|c|}
\hline \multirow[t]{2}{*}{ Model } & \multicolumn{2}{|c|}{$\begin{array}{l}\text { Unstandardized } \\
\text { coefficients }\end{array}$} & \multirow{2}{*}{$\begin{array}{l}\text { Standardized } \\
\text { coefficients }\end{array}$} & \multirow[t]{2}{*}{$\mathbf{t}$} & \multirow[t]{2}{*}{$p$ value } \\
\hline & B & $\begin{array}{l}\text { Standard } \\
\text { error }\end{array}$ & & & \\
\hline Glycated $\mathrm{Hb}$ & 6.7 & 2.1 & 0.7 & 5.3 & $0.001^{* *}$ \\
\hline $\mathrm{TG}$ & 0.7 & 0.4 & 0.2 & 1.2 & 0.1 \\
\hline Cholesterol & 0.3 & 0.2 & 0.1 & 1.9 & $0.05^{*}$ \\
\hline LDL & 1.3 & 0.8 & 0.3 & 1.1 & 0.09 \\
\hline HDL & 1.7 & 0.9 & 0.8 & 1.0 & 0.1 \\
\hline BMI (SDS) & 5.1 & 3.1 & 0.4 & 1.5 & 0.08 \\
\hline SBP (SDS) & 3.8 & 2.1 & 0.8 & 1.7 & 0.07 \\
\hline DBP (SDS) & 8.6 & 3.7 & 0.9 & 2.5 & $0.02^{*}$ \\
\hline
\end{tabular}

Dependent Variable: urinary 8-oxodG. Entered factors are: age, Glycated Hb, LDL, HDL, Cholesterol, TG, Body mass index (SDS), systolic blood pressure (SDS), diastolic blood pressure (SDS). ${ }^{*} \mathrm{p} \leq 0.05$ is significant, ${ }^{* *} \mathrm{p} \leq 0.01$ is highly significant

\section{DISCUSSION}

With the expansion of the incidence rate of diabetes, more research is expected to be done to study its pathogenic mechanism and locate the applicable management. Despite the complexity of mechanisms underlying diabetes and its complications, oxidative stress gives a new sight [16]. Oxidative stress is defined as a disturbance of the balance between production and detoxification of reactive oxygen resulting in failure to repair the subsequent damage. This disturbance can lead to harmful impacts through the formation of reactive oxygen species (ROS) leading to disruption of cellular components including nucleic acids, lipids, and proteins $[17,18]$.

Urinary 8-oxodG level was found to be higher in diabetic children in comparison to control in our study. Similar results were found in Chinese study performed on Type 2 diabetic patients, where urinary concentrations of 8-oxodG were obviously higher compared to healthy controls [19]. Levels of urinary 8-oxodG were also positively associated with $\mathrm{HbA1c}$ as these levels were significantly higher in uncontrolled T1DM patients (HbA1c $\geq 8$ ) compared to controlled patients $(\mathrm{HbA} 1 \mathrm{c}<8)$ this was confirmed when a linear regression was applied to predict factors influencing urinary levels of 8-oxodG and finding that $\mathrm{HbA} 1 \mathrm{c}$ is the most affecting factor. This comes in agreement with results of the previous studies showing that poor glycemic control is one of the most important factors that lead to oxidative DNA damage $[20,21]$. Similarly, Dong et al. showed a significant correlation between urinary 8-oxodG and glycated $\mathrm{Hb}$ in the T1DM patients $(r=0.53)$ [19]. These findings can be explained by increased formation of ROS that can lead to the development of multiple DNA lesions; (8-oxodG) is one of the most broadly

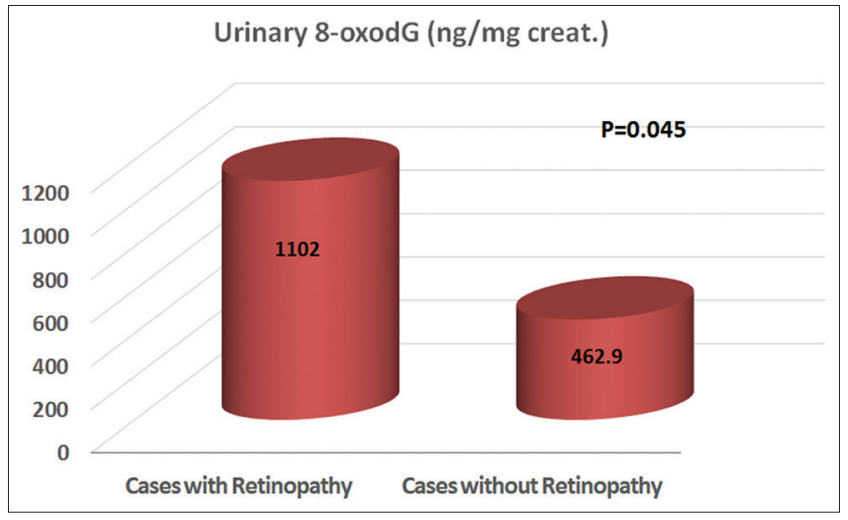

Fig. 1: 8-oxodG levels in diabetic cases with and without retinopathy

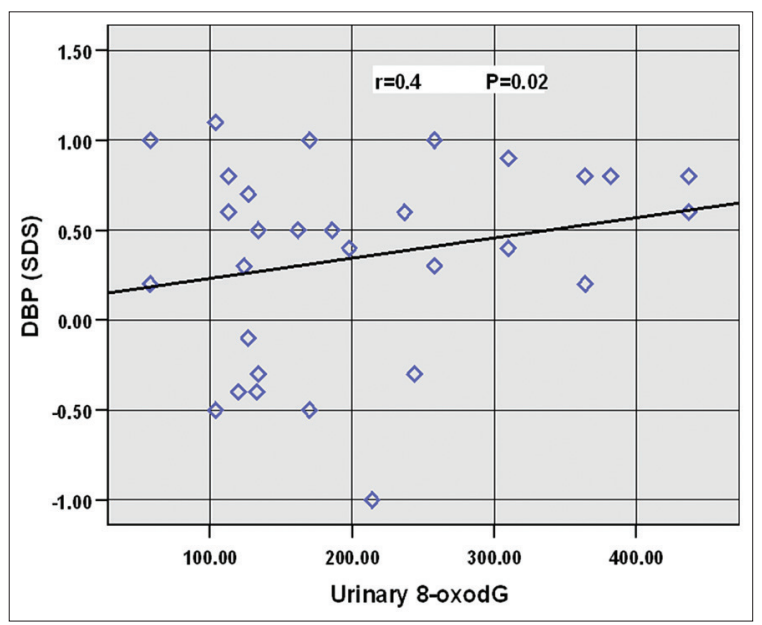

Fig. 2: Correlation between urinary 8-oxodG and diastolic blood pressure (standard deviation score)

examined lesions. The repair products of these lesions are excreted in urine [22]. 8-oxodG was tested in urine rather than in blood, which was explained by the following three reasons. First, blood levels of 8-oxodG were mostly determined by the kidney function, and when different cases were compared, they were unlikely to give accurate data about oxidative anxiety. Furthermore, urine contained a larger amount of oxidized guanosine than blood, hence giving a higher accuracy [23]. Third, the urine sample was obtained noninvasively and more easily than blood.

Diabetic children also have elevated lipid profile (TG, LDL, and cholesterol) and BP (SBP, and DBP) compared to controls. These results coincide with the previous data which proved that $\mathrm{BP}$ and lipid profile are elevated in diabetic children with the presence of positive correlation between DBP with diabetes duration and HbA1c levels [24-26]. The possible relationship between these factors and urinary 8-oxodG had been discussed in only a few studies. Current study findings showed a positive correlation between urinary 8-oxodG and both DBP (SDS) and serum cholesterol. This matches Hinokio et al. findings of increased urinary 8-oxodG levels in hypertensive diabetic patients in comparison to normotensive ones [27]. In the contrary, no significant association was found between urinary 8-oxodG and hypertension in other studies $[21,28]$.

In addition, we found higher urinary 8-oxodG levels in diabetic patients with microalbuminuria in comparison with non-albuminuric patients. Similar results were observed in the previous studies with two-fold higher levels of 8-oxodG in diabetic patients with microalbuminuria compared to T1DM patients with no albumin in urine $[28,29]$. This 
can be explained by the positive association between tubulointerstitial and glomerular injury caused by diabetic state and urinary 8-oxodG excretion [30].

Diabetic patients in this study underwent full ocular examination, and those who were diagnosed with DR had significantly elevated urinary 8-oxodG concentrations compared to those with no retinopathy. This comes in agreement with results of the previous works that assessed the relationship between the degree of retinal affection in diabetic patients and their urinary levels of 8-oxodG [31]

Again, we can refer the previous diabetic microvascular complications to the oxidative damage that happens when the ROS level overpowers defensive mechanisms, leading to a cellular imbalance between pro- and antioxidant factors [32]. Elevated levels of oxidation markers such as 8-oxodG most likely prompt to strand breaks and oxidative base changes; and multiple signaling pathways that may likewise add to the unfavorable impacts of glucotoxicity on cellular functions $[33,34]$.

DNA oxidation can lead to microvascular complications of diabetes through different mechanisms; the most important of them is the induction of cell senescence via either telomeric or non-telomeric DNA damage [35]. This senescence leads to vasculopathy and atherosclerosis and finally the clinical signs of the vascular complications observed in diabetes [36].

In summary, this study demonstrated significantly higher levels of oxidative DNA damage in patients with Type 1 diabetes compared with healthy control subjects, and that Type 1 diabetes patients with complications have increased urinary 8-oxodG excretion compared with those without complications. We propose the role for 8-oxodG as a molecular mechanism contributing to the microvascular complications of Type 1 diabetes. Further studies ought to be initiated to assess the potential clinical applications of 8-oxodG as a biomarker in diabetes that could be used for risk stratification, progressive course, selection of appropriate therapeutic intervention, and the monitoring of response to therapy.

\section{REFERENCES}

1. Soltesz G, Patterson C, Dahlquist G. Diabetes in the Young: A Global Perspective IDF Diabetes Atlas. $4^{\text {th }}$ ed. Pecs, Hungary: Department of Pediatrics; 2009. p. 1-36.

2. Scaramuzza AE, Redaelli F, Giani E, Macedoni M, Giudici V, Gazzarri A, et al. Adolescents and young adults with Type 1 diabetes display a high prevalence of endothelial dysfunction. Acta Paediatr 2015;104(2):192-7.

3. Prabhakar PK. Pathophysiology of secondary complications of diabetes mellitus. Asian J Pharm Clin Res 2016;9(1):32-6.

4. Madan R, Gupt B, Saluja S, Kansra UC, Tripathi BK, Guliani BP. Coagulation profile in diabetes and its association with diabetic microvascular complications. J Assoc Physicians India 2010;58:481-4.

5. Calcutt NA, Cooper ME, Kern TS, Schmidt AM. Therapies for hyperglycaemia-induced diabetic complications: From animal models to clinical trials. Nat Rev Drug Discov 2009;8(5):417-29.

6. Altincik A, Tuglu B, Demir K, Catli G, Abaci A, Böber E. Relationship between oxidative stress and blood glucose fluctuations evaluated with daily glucose monitoring in children with Type 1 diabetes mellitus. J Pediatr Endocrinol Metab 2016;29(4):435-9.

7. Broedbaek K, Siersma V, Henriksen T, Weimann A, Petersen M, Andersen JT, et al. Urinary markers of nucleic acid oxidation and cancer in Type 2 diabetes. Redox Biol 2015;4:34-9.

8. Rochette L, Zeller M, Cottin Y, Vergely C. Diabetes, oxidative stress and therapeutic strategies. Biochim Biophys Acta 2014;1840(9):2709-29.

9. Tatsch E, Bochi GV, Piva SJ, De Carvalho JA, Kober H, Torbitz VD, et al. Association between DNA strand breakage and oxidative, inflammatory and endothelial biomarkers in Type 2 diabetes. Mutat Res 2012;732(1-2):16-20.

10. Lohman TG, Roche AF, Martorell R. Human variation in anthropometric dimensions. In: Anthropometric Standardization Reference Manual. Champaign, IL: Human Kinetics Publishers; 1988. p. 86-107.

11. Group WMGRS. WHO child growth standards: Length/height- forage, weight-for-age, weight-for-length, weight-for-height and body mass index-for-age: Methods and development. In: WHO Press, editors. WHO Child Growth Standards. Geneva, Switzerland: World Health Organization; 2006. p. 312. Available from: http://www.who. int/childgrowth/standards/Technical_report.pdf. [Last accessed on 2011 Aug 11].

12. Wühl E, Witte K, Soergel M, Mehls O, Schaefer F; German Working Group on Pediatric Hypertension. Distribution of 24-h ambulatory blood pressure in children: Normalized reference values and role of body dimensions. J Hypertens 2002;20(10):1995-2007.

13. Friedewald WT, Levy RI, Fredrickson DS. Estimation of the concentration of low-density lipoprotein cholesterol in plasma, without use of the preparative ultracentrifuge. Clin Chem 1972;18(6):499-502.

14. Pagel J. Biographisches Lexikon hervorragender Ärzte des Neunzehnten Jahrhunderts. Berlin: Urban \& Schwarzenberg; 2012. p. 814. Available from: https://archive.org/details/biographisches101pagegoog. [Last retrieved on 2012 Oct 19].

15. Wilkinson CP, Ferris FL $3^{\text {rd }}$, Klein RE, Lee PP, Agardh CD, Davis M, et al. Proposed international clinical diabetic retinopathy and diabetic macular edema disease severity scales. Ophthalmology 2003;110(9):1677-82.

16. Krauss RM. Lipids and lipoproteins in patients with Type 2 diabetes. Diabetes Care 2004;27(6):1496-504

17. Broedbaek K, Weimann A, Stovgaard ES, Poulsen HE. Urinary 8-oxo7,8-dihydro-2'-deoxyguanosine as a biomarker in Type 2 diabetes. Free Radic Biol Med 2011;51(8):1473-9.

18. El-Gindi HD, Hassanin AI, Mostafa NO, El-Kassas GM, El Wakeel MA, El-Batal WH, et al. Oxidative DNA damage in $\beta$-thalassemic children. Med Res J 2015;14(2):41-6.

19. Dong QY, Cui Y, Chen L, Song J, Sun L. Urinary 8-hydroxydeoxyguanosine levels in diabetic retinopathy patients. Eur J Ophthalmol 2008;18(1):94-8.

20. Al-Aubaidy HA, Jelinek HF. Oxidative DNA damage and obesity in Type 2 diabetes mellitus. Eur J Endocrinol 2011;164(6):899-904.

21. Xu GW, Yao QH, Weng QF, Su BL, Zhang X, Xiong JH. Study of urinary 8-hydroxydeoxyguanosine as a biomarker of oxidative DNA damage in diabetic nephropathy patients. J Pharm Biomed Anal 2004:36(1):101-4

22. Wu LL, Chiou CC, Chang PY, Wu JT. Urinary 8-OHdG: A marker of oxidative stress to DNA and a risk factor for cancer, atherosclerosis and diabetics. Clin Chim Acta 2004;339(1-2):1-9.

23. Poulsen HE, Nadal LL, Broedbaek K, Nielsen PE, Weimann A. Detection and interpretation of 8-oxodG and 8-oxoGua in urine, plasma and cerebrospinal fluid. Biochim Biophys Acta 2014;1840(2):801-8.

24. El Wakeel MA, El-Kassas GM, Amer AF, Elbatal WH, Sabry RN, EL-Ghaffar Mohammed NA. E-selectin and vascular complications in children with Type 1 diabetes mellitus. Med Res J 2014;13(1):27-32.

25. Soubra L, Nureddin H, Omar AG, Saleh M. Factors associated with hypertension prevalence and control among lebanese Type 2 diabetic patients. Int J Pharm Pharm Sci 2016;8(10):153-9.

26. Nayak B, Bhaktha G. Inconsistent lipid profiles exhibited among the diabetic Asian Indians of India and trinidad - A comparative study. Int J Pharm Pharm Sci 2016;8(12):60-3.

27. Hinokio Y, Suzuki S, Hirai M, Suzuki C, Suzuki M, Toyota T. Urinary excretion of 8-oxo-7, 8-dihydro-2'-deoxyguanosine as a predictor of the development of diabetic nephropathy. Diabetologia 2002; 45(6):877-82.

28. Nishikawa T, Sasahara T, Kiritoshi S, Sonoda K, Senokuchi T, Matsuo T, et al. Evaluation of urinary 8-hydroxydeoxy-guanosine as a novel biomarker of macrovascular complications in Type 2 diabetes. Diabetes Care 2003;26(5):1507-12.

29. Shimoike T, Inoguchi $T$, Umeda F, Nawata H, Kawano K, Ochi H. The meaning of serum levels of advanced glycosylation end products in diabetic nephropathy. Metabolism 2000;49(8):1030-5.

30. Kanauchi M, Nishioka $H$, Hashimoto T. Oxidative DNA damage and tubulointerstitial injury in diabetic nephropathy. Nephron 2002;91(2):327-9.

31. Tatsch E, De Carvalho JA, Hausen BS, Bollick YS, Torbitz VD, Duarte $\mathrm{T}$, et al. Oxidative DNA damage is associated with inflammatory response, insulin resistance and microvascular complications in Type 2 diabetes. Mutat Res 2015;782:17-22.

32. Liu X, Gan W, Zou Y, Yang B, Su Z, Deng J, et al. Elevated levels of urinary markers of oxidative DNA and RNA damage in Type 2 diabetes with complications. Oxid Med Cell Longev 2016;2016:4323198. 
33. Erusalimsky JD. Vascular endothelial senescence: From mechanisms to pathophysiology. J Appl Physiol 2009;106(1):326-32.

34. Nithya $\mathrm{K}$, Isabel $\mathrm{W}$, Angeline $\mathrm{T}$, Priscilla AS, Asirvatham AJ. Assessment of DNA strand breaks and total antioxidant status in patients with Type 2 diabetes with and without complications: A casecontrol study. Asian J Pharm Clin Res 2017;10(4):430-4.

35. Cooke MS, Olinski R, Loft S; European Standards Committee on Urinary (DNA) Lesion Analysis. Measurement and meaning of oxidatively modified DNA lesions in urine. Cancer Epidemiol Biomarkers Prev 2008;17(1):3-14.

36. Brodsky SV, Gealekman O, Chen J, Zhang F, Togashi N, Crabtree M, et al. Prevention and reversal of premature endothelial cell senescence and vasculopathy in obesity-induced diabetes by ebselen. Circ Res 2004;94(3):377-84. 